\title{
Modelling visual quality of Kalanc
influence of cultivar and pot size
}

\section{Susana M.P. Carvalho ${ }^{1,3}$, Jorge Almeida' ${ }^{1}$, Barbara Eveleens-Clark ${ }^{2}$, Menno J. Bakker ${ }^{1}$ and Ep Heuvelink ${ }^{1}$} susana.carvalho@wur.nl

\section{Introduction \& Aim}

Predicting and controlling the visual product quality and cropping duration is of utmost importance in year-round flowering pot plant production. Explanatory models are valuable tools for optimal greenhouse control and production planning.

In a previous work an explanatory model for plant height and cropping duration was developed and validated for one cultivar and one pot size. The current study aims at extending that model to other cultivars and pot sizes to make it generally applicable in kalanchoe production.

\section{Model development, validation and extension}

- Model development \& calibration (1 Expt. in climate chambers):

- 4 temp. $\left(18,21,23,26{ }^{\circ} \mathrm{C}\right)$ * 4 PPFD $\left(60,90,140,200 \mu \mathrm{mol} . \mathrm{m}^{-2} . \mathrm{s}^{-1}\right)$

- 1 cultivar ('Anatole') and 1 pot size $(10.5 \mathrm{~cm} \emptyset)$

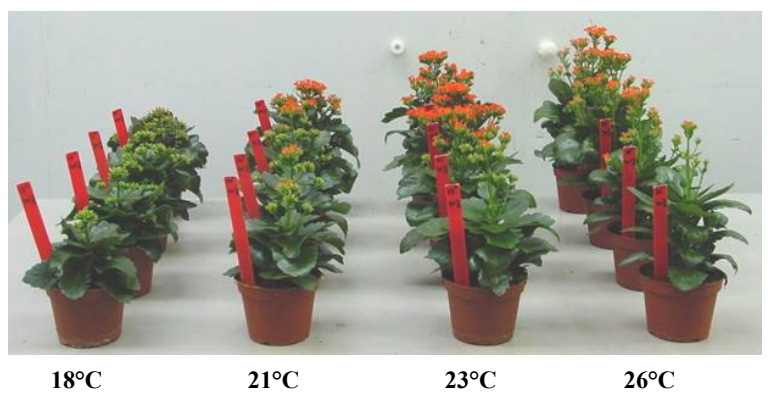

200

140

90

60

$\mu \mathrm{mol} . \mathrm{m}^{-2} \mathrm{~s}^{-1}$

- Model validation (2 Expt. in a commercial nursery: winter and summer):

- 1 cultivar ('Anatole') and 1 pot size $(10.5 \mathrm{~cm} \varnothing)$

Model extension (2 Expt. in a commercial nursery: winter and summer):

- 8 cultivars (see Photo) and 2 pot sizes ( 7 and $10.5 \mathrm{~cm} \varnothing)$

\section{Results}

The studied cultivars showed a strong variation when grown under the same conditions (values provided for $10.5 \mathrm{~cm}$ pot and summer):

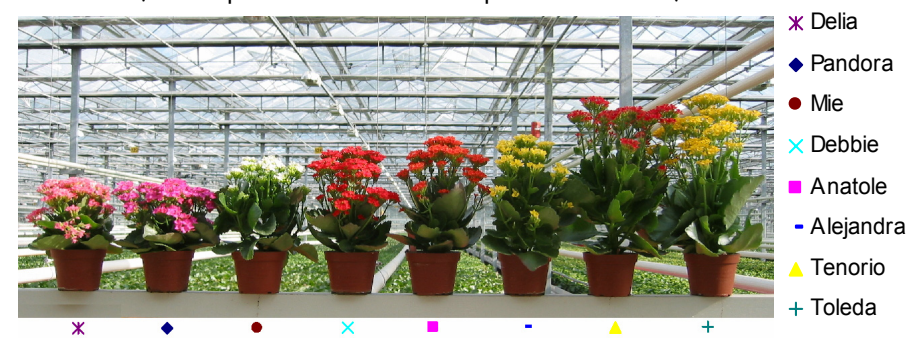

$\square$ Plant height $\rightarrow$ varied from $10.2 \mathrm{~cm}$ 'Delia' to $25.6 \mathrm{~cm}$ 'Toleda'

Reaction time (i.e. days from start of short-day period to harvest)

$\rightarrow$ varied from 55 days 'Debbie' to 64 days 'Mie'

\section{1) Reaction time}
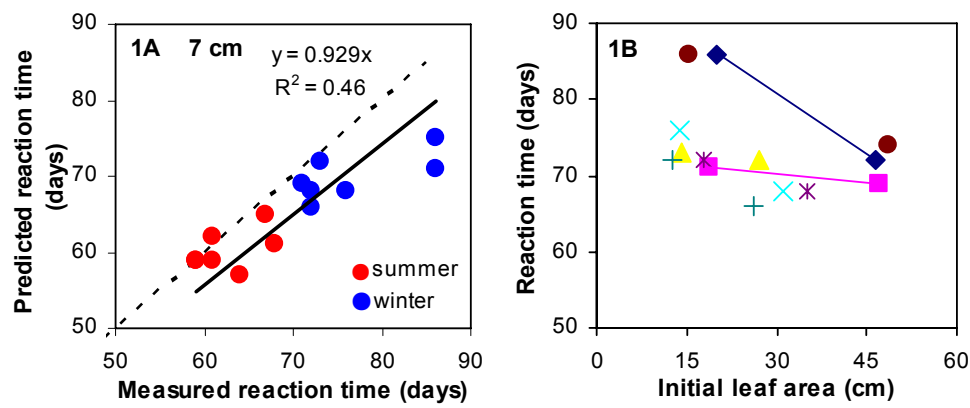

Model predicted accurately the reaction time of different cultivars grown in $10.5 \mathrm{~cm}$ pots (only $1.4 \%$ overestimation; data not shown)

- Smaller pots $(7 \mathrm{~cm} \emptyset) \Rightarrow$ longer reaction time, specially during winter. This resulted in a overall underestimation of $7 \%$ (Fig. $1 \mathrm{~A}$ ) and is related to the lower initial leaf area (LA) present in smaller pots (Fig. 1B)

- The sensitivity of reaction time to the initial LA is cultivar dependent (Fig. 1B)

\section{2) Plant height (vegetative and generative length)}
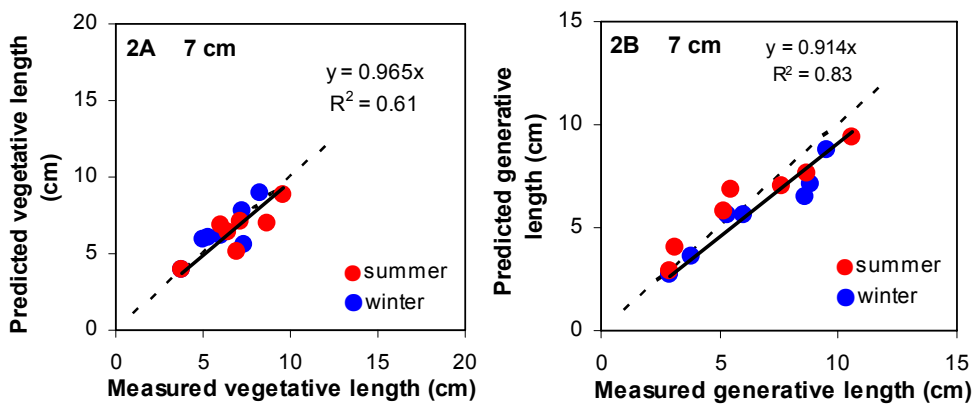

Model predicted accurately vegetative length and generative length for both pot sizes: only a small general underestimation was observed (Fig. $2 \mathrm{~A}$ and $2 \mathrm{~B}$; data not shown for $10.5 \mathrm{~cm}$ ), mainly due to shorter internodes found in the commercial nursery Expt. as compared to the climate chamber Expt.

The framework of the explanatory model previously developed for one cultivar was successfully adapted to other kalanchoe cultivars and pot sizes. To implement this dynamic model to predict plant height and reaction time for different cultivars in multiple growth conditions, only few parameters need to be quantified and compared to the reference cultivar at one light and temperature condition (i.e. average maximum vegetative internode length, internode appearance rate, generative length and reaction time).
1) Horticultural Production Chains Plant Sciences Group - Wageningen University Marijkeweg 22 6709 PG Wageningen The Netherlands http://www.hpc.wur.nl/uk
2) Wageningen UR Greenhouse Horticulture P.O. Box 20 2665 ZG Bleiswijk The Netherlands

http://www.greenhousehorticulture.wur.nl/
3) College of Biotechnology Portuguese Catholic University Rua Dr. António Bernadino de Almeida, 4200-072 Porto

Portugal

http://www.esb.ucp.pt 